\title{
Telling Stories to Develop Empathy: An Experiential Exercise for Future Leaders
}

\author{
Marco Aponte-Moreno \\ Saint Mary's College of California
}

Empathy is often defined as the ability to comprehend another person's feelings and to re-experience them oneself. Although it has commonly been recognized as an essential leadership skill, its teaching and development have not received a lot of attention in the leadership literature. This article presents the Global Citizen Story (GCS), an experiential exercise aimed at developing leaders' empathetic skills in crosscultural settings. The exercise, which requires that students write and tell a fictitious story in the first person, consists of four stages: researching, imagining, writing, and telling the story. The exercise allows students to empathize with a person from another culture who is facing a serious challenge. It targets the empathetic skills of both the students telling the stories and those listening to the stories. Although the exercise was created in the context of a global business MBA course, it can be adapted to any course aimed at developing empathy as an essential leadership skill.

Keywords: leadership, leadership development, empathy, empathetic skills, storytelling

\section{INTRODUCTION}

Empathy can be defined as the capacity to comprehend the feelings of another person and to reexperience them oneself. It consists of two dimensions: a cognitive one, which is related to understanding another person's feelings, and an affective one, which involves feeling what the other person is feeling. Empathy is more than simple sympathy, which involves the ability to understand and support others with sensitivity and compassion (Holt \& Marques, 2012; Salovey \& Mayer, 2004).

In the leadership literature, empathy is often mentioned, either explicitly or implicitly, as an important leadership skill (Wilson, 2015). Leadership theories such as transformational leadership, charismatic leadership, servant leadership and authentic leadership associate empathy to effective leadership (Bass, 1990; Shamir et al, 1993; Northouse, 2010; Walumbwa et al, 2018). The construct is also an integral part of the definition of emotional intelligence, which is considered an essential trait of effective leaders (Goleman, 2004). Empathetic leaders are more effective in inspiring followers to achieve common goals. Their understanding and support of followers improves followers' behaviors and affective states (Kock et al, 2018).

This article presents the Global Citizen Story (GCS), an experiential exercise aimed at developing leaders' empathetic skills in cross-cultural settings. The exercise, which requires writing and telling a fictitious story in the first person, consists of four stages: researching, imagining, writing, and telling the story. 


\section{Learning Objectives}

1. Increase student's knowledge and awareness of similarities and differences between people from different parts of the world by conducting research of a specific culture found in a country different from the student's country.

2. Apply the newly acquired knowledge of the chosen culture by creating a fictional character from the country where the culture exits, and by imagining the character's needs, circumstances, obstacles, relationships and behaviors.

3. Develop the student's mindfulness in relation to the chosen culture by writing a story based on the fictional character's efforts to overcome difficult circumstances in the character's country.

4. Develop the empathetic skills of both the students telling the stories and those listening to the stories every week.

\section{THE EXERCISE}

The Global Citizen Story was developed for a graduate course in international business. The course is part of the curriculum of a Master in Business Administration (MBA) at a liberal arts college in Northern California. Since one of the objectives of the course is to train students to work in global contexts, the exercise aims at developing students' empathetic skills so that they can conduct businesses effectively and responsibly when dealing with other cultures. The exercise consists of four steps: (1) Researching; (2) Imagining; (3) Writing; and (4) Storytelling. In the following sections, I will first review the four steps of the exercise and then I will discuss my classroom experience with it. The assignment given to students can be found in Appendix A.

\section{Step 1: Researching}

In the first step of the exercise, the student picks a challenging issue in a specific country where the fictitious character will be from. Then the student conducts a thorough research of the issue, the country and the character's culture. For example, a student could pick the difficulties that Venezuelans are currently facing as a result of the collapse of their economy. Thus, the student will thoroughly research the issue and the country, and will then create a fictious character from Venezuela who is facing severe circumstances related to the issue (like for example being in extreme poverty and unable to find a job).

It is important that students understand that a given country does not contain only one single culture. Instead, they should think of countries as containers of different cultures, which vary depending on regions, ethnicities, socio-economic factors, etc. (Taras et al, 2016). When they research the character's culture, they need to be specific so that they can address the distinctive traits of their characters' true cultures. Students are encouraged to watch videos of people from the place and culture that they are exploring in order to get a deeper understanding of their values, beliefs and behaviors. Adequate videos can be found on the websites of Human Rights Watch and UN News.

The research phase can be adapted to the needs of the particular class being taught. For example, in the context of our MBA class in international business, the selection of the country and the issue were facilitated by regular class discussions of international news. In order to avoid bias in the research stage, students are expected to use reliable sources consisting of publications by established organizations and reputable press. Appendix B includes the list of online sources recommended for this exercise in our MBA international business course.

\section{Step 2: Imagining}

In the next step of the exercise, the student imagines the character. It is important to note that although the character is an imaginary person, most of the circumstances faced by the character are real. They are based on the student's research of the specific country and culture. In order to guide the student in the imagination process, the following questions should be answered from the perspective of the character. These questions are borrowed from the theater, and are often used by actors when creating and imagining their characters. They are taken from the acting method developed by Uta Hagen, the renowned American 
acting teacher and actress. The questions are as follows: Who am I? What are my circumstances? What are my relationships? What do I want? What's in my way? What do I do to get what I want? (Hagen, 1991). Hagen's approach seems ideal for the GCS, given that the ultimate goal is for students to understand and empathize with their characters, as well as for the audience (the class) to feel the characters' needs and struggles. It is important to note that drama and fiction have proven to be effective tools in cultivating empathy (Metcalf, 1931; Rowe, 2018; Verducci, 2000).

\section{Step 3: Writing}

After the student knows the character well, the story should be written in the first person. Although the structure of the story should be left to the student's creativity, a basic structure could be suggested. According to Gustave Freytag, the famous $19^{\text {th }}$ century German novelist and playwright, the story should be built around a conflict. It could be a conflict with others, with society, with a system, etc. He distinguishes five parts in the story's structure (Freytag, 2010): (1) exposition (introduction of time, place, characters, mood, etc.); (2) rising action (emergence of the conflict); (3) climax (turning point of the story; the conflict is at its peak), (4) falling action (story starts to calm down, moving toward a satisfactory ending), (5) resolution (conflict gets resolved; end of the story). Appendix C illustrates this structure.

In courses having an international or intercultural component, it is important that the character featured in the story be from a different culture from the student's in order to target the development of the student's intercultural skills, as well as to make the empathy goal of the activity more challenging.

\section{Step 4: Storytelling}

The final step takes place in the classroom (or via zoom for online classes) and consists of the actual telling of the story. Ideally the student should not read the story. She or he should sit (or stand) in front of the class and tell the story in the first person. By using the first person, the student is given the opportunity to internalize the character and the circumstances in a much more personal way than if it was done in the third person. To a certain extent, the use of the first person allows the student to embody the character.

After the student tells the story, the class asks questions to the student (who answers in character) about the character's circumstances and needs. In answering these questions, the student is given even more opportunities to embody the character. The activity becomes an improvisation exercise in which students are required to really put themselves in the shoes of their characters in order to answer the questions truthfully. Since different stories are presented every week, the students in the class are given the chance to exercise their empathetic skills every week, when they listen to the stories and ask questions.

This exercise could also be conducted in pairs. In this case, both students work together in the researching, imagining and writing of the story. Then, for telling the story, one student could act as the interviewee (the one who tells the story in the first person) while the other one acts as an interviewer. The pair option gives students the opportunity not only to develop the story together, but also to tell it as a team. This would decrease the anxiety of presenting in front of the class, and would reduce the time devoted to the exercise during the term. Appendix D shows a possible schedule for a class of 28 students working in pairs.

The storytelling part of the GCS is approximately 15 to 20 minutes long. The activity includes a writeup of the story in no more than 2,000 words. In the story it must be clear who the character is, what her/his circumstances are (including the challenge or conflict), what she/he wants, what her/his relationships are, what the big obstacles in achieving the character's objectives are, and what the character does to achieve what she/he wants. These points are based on Uta Hagen's six questions mentioned above in the imagination step.

The six questions target the cognitive component of empathy: understanding the character and the character's circumstances. The "performance" element, which consists of telling the story in the first person and embodying the character as much as possible (especially during the Q\&A part) targets the affective element of empathy. 


\section{DISCUSSION}

The exercise was carried out in three different cohorts of MBA students. There was a total of twentyfive students: eight females and seventeen males. Four students were born in India, five were MexicanAmerican, two were African-American, three were Filipino-American, one was from Canada, and the rest were white American students. Appendix D includes recommendations to adapt the exercise to larger classes.

Topics developed by the students in their stories were diverse. They included both business-related topics such as discrimination in Japanese corporations and non-business topics such as the challenges faced by refugees in Europe. In all stories, characters were put in extreme circumstances, facing life and death situations. The high stakes made the stories compelling while triggering empathy from the class.

It was during the Q\&A that the exercise came to life. When students in the class started to ask their questions, the storyteller really began to embody the character. We saw him or her reacting, thinking and speaking like the character. The Q\&A was the moment when empathy could be seen in the storyteller's and the audience's faces. Some students even cried. Generally, questions were about the reasons behind the choices made by the characters, about how the characters felt, or about the consequences of their actions in others. Appendix E provides a general description of what happens in class when students tell their stories. Appendix F includes an example of a Global Citizen Story.

Overall, the exercise was well-received by the students, who were asked written feedback about what worked and did not work in the exercise. No student identified any aspect that did not work. They commented on the engaging nature of the work: "It allowed me to see different cultural, social and economic issues that individuals encounter when taking a job." They also commented on its innovative dimension: "A new way for us to learn about a culture, country, we are completely unfamiliar with...we were able to analyze how things are at a micro and at a macro level." They emphasized the creative nature of the activity: "The most challenging and creative part of the course was the GCS. That was the highlight of the quarter." And they spoke about the GCS as a good learning experience: "The GCS was a great learning and a great assignment" and "GSC helped learn about countries and cultures."

Considering the surge of online instruction as a result of the COVID pandemic, it is important to note that this exercise does not require any special adaptations. Students conduct the first three steps (researching, imagining and writing) at home, and do the storytelling in the online classroom the same way they would do it in the regular classroom.

\section{CHALLENGES AND LIMITATIONS}

One of the main challenges encountered in the GCS dealt with difficulties related to building trust in the classroom. Since the GCS is an unconventional activity for an MBA setting, it took some time to gain students' trust. This was achieved by explaining in detail the rationale behind creating and telling the stories. Also, the creative aspect of the GCS was a big challenge for many MBA students whose minds are more used to analytical tasks.

In addition, assessing the exercise for grading purposes was a challenge considering the difficulties of measuring affective empathy. The affective empathy component includes the student's ability to connect with the character and her/his circumstances, relationships, obstacles, goals, and actions (based on the sensibility expressed in both the writing and the storytelling). Although in most cases it was clear that students had been moved by their stories, a grade was not assigned to their capacity to express emotions, mainly to avoid that they feel the need to force emotions while telling their stories. However, in Appendix $\mathrm{G}$, which includes both the assessment grid used in the exercise as well as an improved assessment grid, I have included for reference a rubric on affective empathy in the improved version of the grid.

Another challenge had to do with the presentation element of the activity. Although students were used to presenting on a regular basis as part of their graduate studies, the activity generated anxiety in some of them, similar to stage fright. This was overcome by allowing the students who were experiencing anxiety to read the stories as opposed to just telling them to the class. Unfortunately, when the story was read, the 
student was unable to connect with the character in the same way as those students who didn't read. However, the real embodiment happened after the reading, during the Q\&A section. Another possibility to overcome the anxiety issue would be to have students video record their stories ahead of the class. This would likely reduce the anxiety associated with the live presentation. This way, class time could be devoted to the Q\&A part of the exercise, which is often when students embody their characters.

Finally, since students write and tell stories as characters from cultures different from their own, the GCS has the potential of being mistaken by cultural appropriation. This of course is not the case. When we speak about cultural appropriation, we generally mean "the adoption or exploitation of another culture by a more dominant culture" (Oluo, 2018, p.146). In the GCS, cultures are neither adopted nor exploited. Instead, the exercise allows students to explore another culture in order to understand it better. Rather than cultural appropriation, the GCS is an example of cultural appreciation given that the main goal of the exercise is to empathize with people from the culture being explored.

\section{CONCLUSION}

The Global Citizen Story (GCS) is an exercise designed to develop empathy in leaders or aspiring leaders in cross-cultural settings. Through research, imagining, writing and storytelling, the GCS allows students to empathize with a person in another country who is facing a serious challenge. Although the GCS presented some challenges in its execution such as building trust, assessing affective empathy for grading purposes, and overcoming stage fright, the exercise proved to be an interesting and enjoyable way to develop empathy, not only among students telling the stories, but especially among those listening to the stories every week.

\section{REFERENCES}

Bass, B. (1990, Winter). From transactional to transformational leadership: Learning to share the vision. Organisational Dynamics, pp. 19-31.

Freytag, G. (2010). Freytag's technique of the drama: An exposition of dramatic composition and art (M. E. Elias, Trans.). Chicago, IL: Nabu Press.

Goleman, D. (2004). What makes a leader? Harvard Business Review, 82(1), 82-91.

Hagen, U. (1991). A challenge for the actor. New York: Scribner.

Holt, S., \& Marques, J. (2012). Empathy in leadership: Appropriate or misplaced? An empirical study on a topic that is asking for attention. Journal of Business Ethics, 105(1), 95-105.

Kock, N., Mayfield, M., Mayfield, J., Sexton, S., \& De La Garza, L. (2018). Empathetic leadership: How leader emotional support and understanding influences follower performance. Journal of Leadership \& Organizational Studies, 26(2), 217-236.

Metcalf, J.T. (1931). Empathy and the actor's emotion. The Journal of Social Psychology, 2, 235-239.

Northouse, P. (2010). Leadership. Thousand Oaks, CA: Sage Publications.

Oluo, I. (2018). So you want to talk about race. New York: Seal Press.

Rowe, D.B. (2018). The "novel" approach: Using fiction to increase empathy. Virginia Libraries, 63(1).

Salovey, P., Mayer, J., \& Caruso, D. (2004). Emotional intelligence: Theory, findings, and implications, Psychological Inquiry, 15(3), 197-215.

Shamir, B., House, R.J., \& Arthur, M.B. (1993). The motivational effects of charismatic leadership: A self-concept based theory. Organization Science, 4(4), 577-594. http://dx.doi.org/10.1287/orsc.4.4.577

Taras, V., Steel, P., \& Kirkman, B.L. (2016). Does Country Equate with Culture? Beyond Geography in the Search for Cultural Boundaries. Managing International Review, 56, 455-487.

Verducci, S. (2000). A moral method? Thoughts on cultivating empathy through method acting. Journal of Moral Education, 29, 87-99. 
Walumbwa, F.O., Avolio, B.J., Gardner, W.L., Wernsing, T.S., \& Peterson, S. (2008). Authentic leadership: Development and validation of a theory-based measure. Journal of Management, 34(1), 89-126. https://doi.org/10.1177/0149206307308913

Wilson, E. (2015, September). Empathy is still lacking in the leaders who need it most. Harvard Business Review. Retrieved from https://hbr.org/2015/09/empathy-is-still-lacking-in-the-leaders-who-needit-most

\section{APPENDIX A: THE GLOBAL CITIZEN STORY ASSIGNMENT}

The purpose of this exercise is to allow you to really understand and empathize with a person in another country who is facing a serious challenge. The exercise consists of a story (similar to a monologue), delivered in the first person singular, about the life and challenges of an imaginary person who lives overseas. The activity includes a write-up of the story in no more than 2,000 words. The person featured in the story has to be from a different culture from yours in order to develop your intercultural skills.

Preparation: Before starting to work on the exercise, you need to select a country. Then you will imagine the character. It is important to note that although the character is an imaginary person, the circumstances of that character are real. They are based on your research of the selected country. All stories must be built around a challenge (or conflict) that the character is facing.

Presentation: The story will be told to the class in the first person. By embodying your character during the storytelling, you are expected to acquire a deep understanding of the characters' circumstances. The higher the stakes are for the characters, the more interesting the presentation will be. During the presentation, it must be clear who the character is, what her/his circumstances are (including the challenge or conflict), what she/he wants, what her/his relationships are, what the big obstacles in achieving the character's objectives are, and what the character does to achieve what she/he wants. If possible, stories should be learned and told to the class without reading. Stories will be followed by a Q\&A session. You will answer in character. It is in the Q\&A part of the exercise, when you answer unexpected questions from the class, that the most clear embodiment of the character takes place.

Assessment: The activity will be assessed based on three criteria: (a) Level of cognitive empathy: thorough understanding of the character as well as the character's goals and actions (50\%), (b) Level of research: as evidenced by a thorough development of the character's circumstances, relationships and obstacles (25\%), and (c) clear written and oral presentation (25\%). 


\section{APPENDIX B: RECOMMENDED ONLINE SOURCES FOR THE GCS ACTIVITY USED IN OUR MBA COURSE IN INTERNATIONAL BUSINESS}

- On international news

- BBC World News: https://www.bbc.com/news/world

○ The Guardian (World News): https://www.theguardian.com/world/all

○ The Washington Post (World News): https://www.washingtonpost.com/world/

- The New York Times (World News): https://www.nytimes.com/section/world

- On business issues in global contexts

○ World Street Journal (Global News): https://www.wsj.com/news/world

○ Bloomberg: https://www.bloomberg.com

- Business Insider (International News): https://www.businessinsider.com/international

- On general traits of cultures

○ HRAF - Explaining Human Culture: https://hraf.yale.edu/ehc/summaries

- Hofstede Insights: https://www.hofstede-insights.com/product/compare-countries/

○ Globe Project: https://globeproject.com

- On issues faced by people around the world

- UN News (Global Perspectives, Human Stories): https://news.un.org/en/

○ Human Rights Watch: https://www.hrw.org

○ Amnesty International: https://www.amnesty.org/en/

- On global statistics

○ UN Statistics: http://data.un.org

○ CIA World Factbook: https://www.cia.gov/library/publications/the-world-factbook/

\section{APPENDIX C: GUSTAV FREYTAG'S DRAMATIC STRUCTURE}

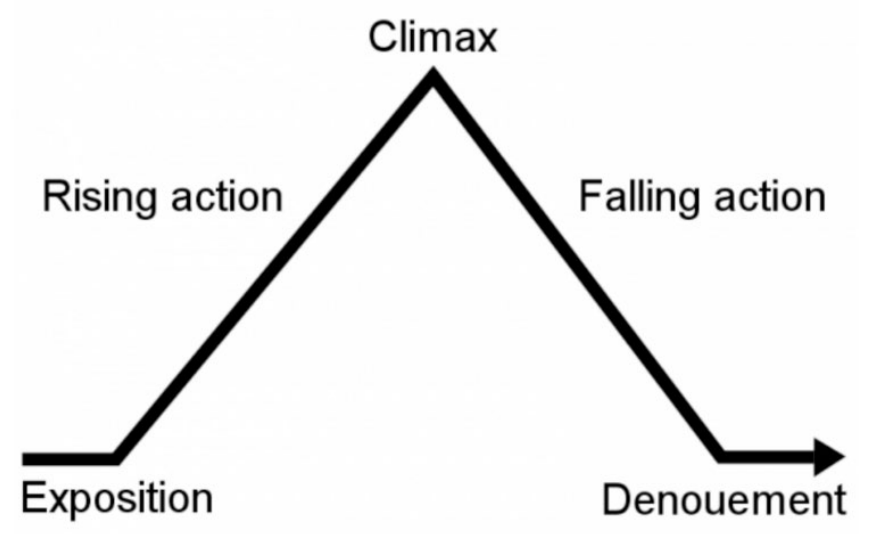




\section{APPENDIX D: RECOMMENDED FOR LARGER CLASSES}

The MBA classes in which the GCS was first carried out were smaller than 10 students per course and lasted 10 weeks. Each class was 4 hours. The exercise was scheduled so that there were two presentations per class during the last five weeks of the term.

In general, each student took 15 to 20 minutes per presentation. This was followed by the Q\&A, which generally lasted around 10 minutes. Thus, the GCS exercise took approximately 30 minutes of class time per student. This was ideal for our small MBA classes, but needs to be adapted for bigger classes.

For classes between 20 to 30 students, the length of the GCS could be reduced from 2,000 words to 1,000 words. This would reduce the duration of the exercise by half. Thus, the GCS exercise would take approximately 15 minutes of class time per story. If the large class takes place in a 10-week term, the GCS presentations could start earlier instead of on week 5.

In addition, the exercise could be conducted in pairs. Both students would work together in the researching, imagining and writing of the story. Then, for telling the story, one student could act as the interviewee (the one who tells the story in the first person) while the other one acts as an interviewer. The pair option seems like a more reasonable and practical approach, not only because it reduces the time of the exercise in class by half, but also because it gives students the opportunity to work together. The following table shows a possible schedule for a class of 28 students working in pairs.

\begin{tabular}{|c|c|}
\hline & $\begin{array}{l}\text { Class of } 28 \text { student } \\
\text { (Pair Exercise) }\end{array}$ \\
\hline Week 1 & $\begin{array}{l}\text { Introduction of the exercise. Researching and Imagining stages start at } \\
\text { home. }\end{array}$ \\
\hline Week 2 & Continuation of Researching and Imagining stages at home \\
\hline Week 3 & Start of Writing stage at home for students presenting on week 4 \\
\hline Week 4 & $\begin{array}{l}\text { Pairs } 1 \& 2 \\
(30 \text { minutes })\end{array}$ \\
\hline Week 5 & $\begin{array}{l}\text { Pairs } 3 \& 4 \\
(30 \text { minutes })\end{array}$ \\
\hline Week 6 & $\begin{array}{l}\text { Pairs } 5 \& 6 \\
(30 \text { minutes })\end{array}$ \\
\hline Week 7 & $\begin{array}{l}\text { Pairs } 7 \& 8 \\
(30 \text { minutes })\end{array}$ \\
\hline Week 8 & $\begin{array}{l}\text { Pairs } 9 \& 10 \\
(30 \text { minutes })\end{array}$ \\
\hline Week 9 & $\begin{array}{l}\text { Pairs } 11 \& 12 \\
(30 \text { minutes })\end{array}$ \\
\hline Week 10 & $\begin{array}{l}\text { Pairs } 13 \& 14 \\
(30 \text { minutes })\end{array}$ \\
\hline
\end{tabular}




\section{APPENDIX E: GENERAL DESCRIPTION OF WHAT HAPPENS IN CLASS WHEN A STUDENT PRESENTS A STORY}

- First the student comes to the front of the class and sits down. Some students in our MBA classes chose to stand instead.

- Then, before the student starts telling the story, and to make her or him more comfortable with the exercise and get into character, I ask the student a couple of general questions about the story. The student is expected to answer in character (in the first person). The questions I ask are related to the identity of the character as well as the time and place where the character is at the moment: Who are you? Where are you now? What's today's date? What time is it?

- As soon as the questions are answered, I ask the student to start telling the story. During the storytelling time no questions are asked. The student is not interrupted.

- When the student ends the story, I ask the class to start asking questions to the student, who answers in character. The class talks to the student as if they were talking to the character. In general, it is during this dialogue between the student and the class that the real embodiment of the character takes place. It is also during this dialogue that the class really connects with the story and the character, which contributes to the development of the empathetic skills of the whole class.

- During the Q\&A, the class usually asks questions about the reasons behind the choices made by the characters (Why did you do it? Did you consider other options? What could have changed your decision?, etc). Often students also ask about how the character felt when she or he was in the situations described in the story (How did you feel? Did it make you feel happy or sad? Were you angry about what happened?, etc.). It is also common for the class to ask about the consequences of the character's decisions (What happened after your decision? Were you aware of the impact of your choice? Do you regret it?). It is generally during the Q\&A that we can see the extent to which both the storyteller the class have really connected with the story.

- At the end of the Q\&A, when I tell the student that the exercise is over, she or he stops being the character and takes her or his own identity again. It is very interesting to see the student's transformation as soon as they come out of character. They go from whichever emotional state the character was during the Q\&A to being themselves again. At this point I often ask the student how she or he feels. This makes the student reflect on the experience of having embodied the character. We generally speak about the process and discuss the main challenges of the exercise. This final discussion allows the whole class to learn from the student's experience.

- It is important to remember that the exercise is aimed at triggering both the student's and the class' empathy. Thus, the GCS gives the class the opportunity to exercise their empathetic skills every week, when a new story is presented.

\section{APPENDIX F: EXAMPLE OF A GLOBAL CITIZEN STORY}

My name is Yoko Matsumoto, I am an entrepreneur and professional Sushi chef in Osaka, Japan. I am one of the very few female Sushi chefs in Japan. Yes, you heard it right a "female Sushi chef."

I am here to tell my story and share the challenges that I have faced due to the gender inequality issues that still prevail in many parts of Japan. Through my story I am hoping to raise awareness of the situation, and also to encourage other Japanese women to act.

I grew up in Osaka, a port city in the mid-western part of Japan, very well known for its food. I am an only child. Growing up I rarely saw my father, given that he would go to work very early in the morning and get back home late at night. My father owned a Sushi restaurant, he was a very hard-working man. My mom used to work as a bank clerk, but after she gave birth to me she quit her job to take care of the family. This is a very typical situation in traditional Japanese families.

Growing up I always wanted to follow my father's footsteps: become a Sushi chef and have my own restaurant someday. So, I took any opportunity to help my father in his Sushi business. I always insisted that my father train me and help me become a Sushi chef. But my father was always reluctant to take me 
under his wing because it was completely against the norms to have a female behind the Sushi bar. There are areas women in Japan are discouraged to enter into; becoming a Sushi chef is one of them. My story is a small example of the bigger gender inequality and narrow mindset problem that exists in Japanese society.

Historically, Japanese society has always been dominated by men. Men work and make money while women take care of the household. It was around World War II when women got into the workforce to help the country's army in various areas, ranging from making ammunitions in factories to acting as "comfort women" for the army personnel. Gradually after World War II, women joined the workforce but were never given high status jobs or considered equal in the workplace. In fact, they have often been discouraged from working.

Many of my Japanese girlfriends who graduated from top schools have told me how they are rarely selected for management positions in their companies just because they are women. One of the reasons given to them is that they are not going to be able to perform at work if they get pregnant. They have also mentioned that some interviewers even ask potential female employees if they are planning to have children soon. Unfortunately, workplace discrimination towards women is still very prevalent in our country. The current wage gap between male and female workers in Japan is estimated to be between $30 \%$ and $40 \%$. Only $7.4 \%$ of Japanese companies have women in leadership positions. The same applies to women in government, who account for only $12 \%$ of all public officials in Japan.

Although I am not working for a company where I have to go through that kind of workplace discrimination, I am dealing with similar challenges as a sushi chef. Trying to establish myself in a maledominated business within a gender-biased society has been the biggest challenge of my life. This challenge has shaped who I am today, both as a woman and as a professional sushi chef.

My father taught me that once you have decided on an occupation, you must completely immerse yourself in it in order to be successful. You have to fall in love with it, be passionate, and never complain about it. You have to dedicate your life to master the craft. So, that is exactly what I did. I fell in love with making sushi. It became my reason of being, my passion and my life. I was his apprentice for a while. It took me years before he trusted me with the business, before he accepted me as a fellow chef. I know he was proud of me although he never really said it. That's not the way he was. My father believed in hard work, not in compliments. But I know he was proud of me because after years and years of training he finally trusted me with his business, which was his biggest treasure.

Despite my father's approval, my situation as a chef continued being very challenging. I remember a few times, when my father was not in the restaurant and I was managing things, that some customers would go away without ordering anything the moment they saw me. They just didn't trust a woman as a sushi chef. It was very frustrating but I didn't let them upset me because I knew I belonged there.

I have my own Sushi restaurant now, and a few lady apprentices who help me and want to follow my lead. To run your own Sushi restaurant, you have to be very tough. It takes long work hours, regular visits to the local fish market, good relationships with vendors and customers. Quality, consistency and cleanliness are essential, so you need to check them every day. I usually end up spending more time in my restaurant than at home.

This week I'm turning 30 years old. This is an important time for me. Not because of the age, but because I have a boyfriend with whom I would like to start a family. Yes, I am a woman chef who also wants to start a family. Unfortunately, because of the way our society is, I'll be facing a lot of opposition and discrimination. But these challenges are not going to stop me. I will be a successful Sushi chef, a wife and a mother. I don't think that is too much to ask.

Most working women in Japan today are facing similar challenges to the ones I have faced. They are scared to start a family, and in many cases prefer to stay single so that they can continue working. No wonder our population keeps declining year after year. The current population growth rate in Japan is minus $0.23 \%$. Yes, you heard it right: minus $0.23 \%$. And you know why? Because the gender discrimination in our country is preventing working women from starting a family. I wish the mindset was different. I wish we had a proper support system. I wish men and women were treated equally. Unfortunately, it is not the case.

Journal of Leadership Accountability, and Ethics Vol. 18(5) 2021113 
Through my story, I hope that more and more women in our country will challenge the status quo. It is time to stand up and fight for our rights. I want my story to be an inspiration to other Japanese women. We need equality in our society. Only us, women, can make it happen. We have to act now, for us and for our daughters. Nobody will do it for us.

Written by Mr. Anil Mishra MBA Student

Note: It is interesting to note that the student who wrote and told this story was a man in his 40s from India who works in the tech industry. The character he created is a 30-year-old woman from Japan who works as a sushi chef. The student and his character are different in at least four dimensions: gender, age, nationality and profession.

\section{APPENDIX G: SUGGESTED FEEDBACK GRID}

Global Citizen Story - Feedback Sheet

Date:

Topic:

Student(s):

\begin{tabular}{|l|l|}
\hline \multicolumn{1}{|c|}{ Criteria } & Comments \\
\hline $\begin{array}{l}\text { Quality of Content of the Story: The student wrote an imaginative and interesting } \\
\text { story about a fictional character from another culture facing difficult circumstances. } \\
\text { The character and her/his circumstances are believable and based on research. (20\%) }\end{array}$ & \\
\hline $\begin{array}{l}\text { Level of Cognitive Empathy: The student shows a good understanding of the } \\
\text { character and her/his circumstances as they relate to the country and, when applicable, } \\
\text { to the industry and company. It is clear who the character is; what her/his } \\
\text { circumstances, relationships, challenges, objectives and actions are. (20\%) }\end{array}$ & \\
\hline $\begin{array}{l}\text { Level of Affective Empathy: The student expresses believable emotions both in } \\
\text { writing and during the telling of the story. The emotions correspond well with the } \\
\text { circumstances and challenges faced by the character. (20\%) }\end{array}$ & \\
\hline $\begin{array}{l}\text { Evidence of Adequate Research: The story includes facts taken from reliable } \\
\text { sources, which appear at the end of the story. These facts correspond well with the } \\
\text { story and enrich it. They are not just in the story for the sake of listing them. (20\%) }\end{array}$ & \\
\hline $\begin{array}{l}\text { Quality of Presentation: Both the written and the oral presentation of the story show } \\
\text { attention to detail and professionalism. The story has no typos; it is clear and well } \\
\text { structured. (20\%) }\end{array}$ & \\
\hline
\end{tabular}

Grade:

1. Note: It is recommended to use this rubric not only as a tool for the instructor to grade the exercise, but also as a way to collect anonymous feedback from the students in the class. This would allow the instructor to check on students' understanding of the concepts and to confirm his or her assessment. 